\title{
“Três árias” de Frank O’Hara
}

Beatriz Bastos

Resumo: Neste trabalho, além de uma breve introdução ao poeta norte-americano Frank O’Hara, propomos uma tradução comentada do poema “Three airs", que nos parece representativo da estética de O’Hara em sua busca por movimento e abertura. Enquanto proposta tradutória, procuramos não perder de vista a complexidade do texto poético e seus diversos níveis de efeitos - semânticos, rítmicos, prosódicos, etc - empenhando-nos em traduzir ao menos uma boa parte desses aspectos.

Palavras chave: Frank O’Hara; tradução; poesia.

\section{O poeta}

Frank O’Hara nasceu em 1926 em Baltimore, nos Estado Unidos. Estudou piano desde pequeno, e em 1946, como ex-combatente da Marinha, foi fazer um bacharelado em música em Harvard. Algum tempo depois mudou-se de modo mais definitivo para Nova York. "Quando nós todos", diz O’Hara em uma entrevista, "chegamos ou emergimos como poetas em Nova Iorque, no meio e no final dos anos 50, os pintores eram os únicos interessados em qualquer tipo de poesia experimental, o que a cena literária geral não estava"1 (1975, p. 3, tradução nossa). Sua vida em Nova Iorque é quase inseparável de sua relação com a pintura. Além da cidade, do concreto, do metrô - "Eu mal desfruto de uma folha verde ao menos que saiba que tem um metrô por perto, ou uma loja de discos, ou qualquer outro sinal de que as pessoas não se arrependem totalmente da vida"2 (1995, p. 197,

1 [when we all arrived in New York or emerged as poets in the mid 50s or late 50s, painters were the only ones who were interested in any kind of experimental poetry and the general literary scene was not] 2 I can't even enjoy a blade of grass unless I know there is a subway handy, or a record store or some other sign that people do not regret life.] 
tradução nossa) - ele era um entusiasta da experimentação realizada pelo grupo de pintores representativo do que se tornou conhecido como Expressionismo Abstrato. O'Hara e amigos poetas como John Ashbery, Barbara Guest, Kenneth Koch e James Schuyler, fizeram suas primeiras leituras públicas no Cedar Bar, que era o bar dos pintores, e em galerias de arte. Posteriormente ficaram conhecidos como a New York School of Poetry. Além de poesia, escreviam críticas de artes e realizavam colaborações de diversos gêneros com os artistas. Segundo a crítica americana Marjorie Perloff, noções de arte enquanto processo e do quadro enquanto superfície, inspiradas principalmente pela Action Paiting, influenciariam a forma da poesia de O'Hara, na qual procedimentos sintáticos e prosódicos criariam uma poesia de muita abertura e flexibilidade e de desafio a expectativas. (PERLOFF, 1998).

Mas há também uma importante influência da música, sobretudo de vanguarda. John Ashbery conta que em 1952 eles assistiram juntos a um concerto do pianista David Trudor tocando "Music of changes" de John Cage. Sobre a música que este apresentava, Ashbery comenta na introdução aos Collected Poems de O’Hara:

Tanto na época como hoje em dia o mecanismo do método me escapa; o que importava era que elementos do acaso pudessem se combinar para produzir um trabalho tão bonito e tão claro. Para nós foi mais uma prova, talvez uma prova definitiva, não de que "qualquer coisa vale", mas de que "qualquer coisa pode surgir". (ASHBERY, 1995, p. ix, tradução nossa).

O’Hara publicou poucos livros em vida. Muitos de seus poemas sobreviveram apenas porque estavam copiados em cartas ou porque foram encontrados espalhados pelas gavetas de sua casa por seus amigos. De todo modo, em 1966, ao morreu subitamente após um acidente de carro em Fire Island, já havia uma espécie de culto em torno de sua figura. O estilo de alguns de seus poemas - que o próprio O'Hara cunhou de "I do this I do that" ("Eu faço isso eu faço aquilo") - já era copiado pelos poetas da segunda geração da New York School. São poemas de ocasião, muito alertas ao ambiente circundante, supostamente escritos de forma rápida, em momentos os mais triviais, como o intervalo do almoço - daí o título de um de seus livros, Lunch poems (1964). No entanto, como escreveu o músico Morton Feldman: "Estes poemas, tão coloquiais, tão conversacionais, ainda assim

3 [the actual mechanics of the method escaped me then as it does now; what mattered was that chance elements could combine to produce so beautiful and cogent work. It was a further, perhaps for us ultimate proof not so much of "Anything goes" but "Anything can come out"] 
parecem estar nos alcançando de um algum outro lugar, infinitamente distante" (FELDMAN s/d apud MONTGOMERY, 2010, p. 199, tradução nossa). Talvez porque, como nos revela um olhar mais atento, O'Hara frequentemente intercala versos "coloquiais" ou "cotidianos" com apontamentos mais marcadamente líricos, filosóficos ou fantasiosos. Seja como for, é uma poesia que nos lança em certo estado de atenção, cuja leveza e movimento são, ainda hoje, capazes de surpreender.

\section{Sobre a traduçáo}

O poema que escolhemos apresentar neste trabalho é "Three airs". Foi publicado no livro Lunch poems e, ao nosso ver, apresenta diversos aspectos marcantes da estética de O'Hara: o movimento, certa "abertura", imagens fantasiosas misturadas a elementos mais casuais. Como isso é construído no poema é algo que vamos tentar discernir mais adiante. Por ora, vale acrescentar que, enquanto proposta tradutória, nos guiamos principalmente pelas reflexões sobre tradução poética apresentadas por Paulo Henriques Britto em seus textos e em seu livro $A$ tradução literária (2012). Escreve Britto:

Temos consciência de que o texto poético trabalha com a linguagem em todos os seus níveis - semânticos, sintáticos, fonéticos, rítmicos, entre outros. Idealmente, o poema deve articular todos esses níveis, ou pelo menos vários deles, no sentido de chegar a um determinado conjunto harmônico de efeitos poéticos. A tarefa do tradutor de poesia, será, pois, a de recriar, utilizando os recursos da língua-meta, os efeitos de sentido e forma do original - ou, ao menos, uma boa parte deles. (BRITTO, 2002, p. 54).

Foi, portanto, sem perder de vista a complexidade do texto poético, no qual "toda e qualquer caraterística (...) pode ser de importância crucial" (BRITTO, 2012, p. 119), ao mesmo tempo cientes de que uma "tradução perfeita" é impossível, que nos empenhamos em recriar em português ao menos os principais efeitos de sentido e de forma do original.

4 [these poems, so colloquial, so conversational, nevertheless seem to be reaching us from some other, infinitely distant place]. 


\section{O poema e sua traduçáo}

\section{Three airs}

1.

So many things in the air! soot, elephant balls, a Chinese cloud which is entirely collapsed, a cat swung by its tail and the senses of the dead which are banging about inside my tired red eyes

\section{2.}

In the deeps there is a little bird and it only hums, it hums of fortitude and temperance, it is managing a foundry how firmly it must grasp things! tear them out of the slime and then, alas! It mischievously drops them into the cauldron of hideousness there is already a sunset naming the poplars which see only, watery, themselves

3.

Oh to be an angel (if there were any!), and go straight up into the sky and look around and then

come down

not to be covered with steel and aluminum

glaringly ugly in the pure distances and clattering and

$$
\text { buckling, wheezing }
$$

but to be part of the treetops and the blueness, invisible, the iridescent darkness beyond,

$$
\text { silent, listening to }
$$

the air becoming no air becoming air again 


\section{Três árias}

1.

Tantas coisas no ar! fuligem,

bolas de elefante, uma nuvem chinesa

que já desabou por completo, um gato

balançado pelo rabo

e as sensações

dos mortos que batem e se esbarram

dentro dos meus olhos cansados

2.

Lá nas profundezas vive um passarinho que só cantarola, um canto de coragem

e temperança; administra uma fundição

e como é firme ao pegar as coisas! arranca-as

do limo e depois - oh, céus! - numa travessura

ele as joga no caldeirão da feiura

e já um pôr do sol vem nomeando

os álamos que, aguados, só veem a si mesmos

3.

Ah ser um anjo (se anjos houvesse!) e subir

direto ao e céu e dar uma olhada e depois

descer

sem estar coberto com aço e alumínio

fulgurantemente feio nas distâncias puras e estalando e

estourando, arfando

mas ser parte do topo das árvores e do azul, invisível,

na escuridão iridescente ao longe,

silencioso, ouvindo ao

ar tornar-se não ar tornar-se ar de novo 
O'Hara preenche o ar de imagens e sensações. $\mathrm{O}$ ar, um pássaro, um anjo. Certa vez o poeta escreveu a um amigo que estava satisfeito com determinado poema "porque eu pareço ter conseguido mantê-lo 'aberto', então há muitas possibilidades, ar e tal”' (O'HARA, 1961 apud PERFLOFF, 1998, p. 173, tradução nossa), algo que "Three airs" parece cumprir quase ao pé da letra. Trata-se de um poema em três partes, que podem também ser consideradas três poemas independentes. Cada parte é a descrição de um "ar" específico, como se fosse inesgotável o número de "ares", e O’Hara escolhesse, quase ao acaso, três possíveis. O título, "Three airs", funciona como uma espécie de moldura, de "liga", que reúne sequencialmente as três partes, forçando a conexão entre elas. As partes não se explicam, não se resolvem, o poema não chega a uma síntese ou a um sentido unívoco, e esse é apenas um de seus modos de se manter aberto.

O título em inglês sugere, além de "ares", "árias", movimentos musicais. Uma "ária”, segundo o dicionário Aulete, é: 1. uma peça musical para uma só vOz, geralmente em ópera, oratório ou cantata; 2. qualquer composição para ser cantada; canção, cantiga. De fato, trata-se de um poema bastante musical, pois utiliza amplamente rimas, assonâncias e aliterações, e no qual identificamos também células métricas recorrentes. Alguns versos seguem perfeitamente o padrão deste ou daquele pé métrico, recurso este que certamente influencia a apreensão rítmica do poema, tornando-o "musical" por usar convenções que nossos ouvidos estão preparados para ouvir. E ainda, na medida em que, inevitavelmente, cada tipo de pé ocupa certo lugar na tradição, isso afeta, de modo amplo, a esfera semântica do poema.

O trecho inicial do poema traz uma lista de imagens exóticas: misturam-se bolas de elefantes, nuvens chinesas e gatos. Há um certo sabor circense, pode-se imaginar um apresentador de circo anunciando números e chamando a atenção do público. Além disso, as quatro primeiras linhas são predominantemente datílicas, um metro que, em inglês, é pouco comum, e está ligado à grandiosidade clássica das epopeias. Assim, usar dátilos neste início favorece certo caráter de "anunciação", como quem vai dizer algo importante. As três primeiras linhas são também pontuadas por aliterações internas aos versos, com / s / "so" e "soot") e / k / (“cloud", “collapsed", "cat"). Este padrão de costuras internas à linha de verso é interrompido na quarta linha, mais curta, na qual o / s / de "swung" só vai aliterar com "senses", na linha seguinte. E ocorrem outras mudanças nesta passagem. Há uma mudança

5 [because I seem to have been able to keep it "open", and so there are lots of possibilities, air and such]. 
de pés datílicos para pés anapésticos, uma espécie de antidátilo: vamos de "PÁ pa pa" para "pa pa PÁ". O teor semântico também muda, o poeta fala de "mortos", criando uma obscuridade, uma tensão que não estava tão presente nas imagens anteriores. Neste sexto verso, temos "about", que rima com “cloud" lá em cima, e alitera com "banging" no mesmo verso. No caso, a repetição do som /b/ parece reforçar a ideia de som explosivo contida na ideia de "banging". Estas mudanças são reforçadas pelo aspecto visual do verso "and the senses", que difere dos outros versos e começa mais adiante na linha. O último verso é o único no qual surge um pronome pessoal (" $m y$ ") e onde o eu do poeta aparece de modo mais explícito. Nele, também a assonância em / aj/ é bem marcante, presente em nada menos do que em quatro de suas cinco palavras: "inside", “my”, "tired", "eyes". E, ainda, este verso final é também um dos únicos versos jâmbicos do poema. Considerando que o pé jâmbico é o mais "natural" na tradição da poesia em inglês, não deixa de ser curioso que ele só seja usado por O’Hara no verso final, coincidindo com o único momento em que aparece um "eu" poeta. ${ }^{6}$ Como se o poeta e certa noção de poesia finalmente se encontrassem.

Na segunda "ária", predomina um tom mais narrativo, lembrando um pouco uma fábula infantil, pelo tema do passarinho. Em termos formais, ela é mais frouxa, não há muitos jogos sonoros nem células métricas que pareçam mais que acidentais. Mas "afrouxar" a forma não significa perdê-la. A aliteração em / f/ de "fortitude", "foundry" e "firmly" aproxima as palavras que dizem respeito à exemplaridade do passarinho. A repetição de "bums" no segundo verso encena certo caráter repetitivo do canto do passarinho, que não canta por prazer, mas por "fortitude" e "temperance", palavras longas e "cultas", que marcam um certo tom moralizante, coerente com a ideia de fábula infantil. Mas uma moral que certamente não se sustenta muito, pois logo o "little bird" revela-se nada exemplar... O espaço de linha inserido entre os versos cinco e seis "imita" no plano formal a "queda" ("drops them") no caráter do passarinho. E ainda, a repetição da mesma célula métrica - os péons primos de "mischievoushy" e "bideousness" -, ambos proeminentes finais de verso, marcam uma mudança rítmica, ou melhor, criam um padrão onde até agora não parecia haver nenhum movimento mais marcante.

Nos versos finais, abandona-se o tema do passarinho. Aliás, "there is already", no início do penúltimo verso, não tem nenhum referente, e lança-nos bruscamente às imagens surrealistas de um pôr do sol que nomeia e de alámos

6 "Most English verse falls naturally into the iambic pattern." ABRAMS, M. H., et al, 1974, p. 2469. 
que veem. O último verso é costurado pela rima em /e/ entre a tônica de "see" e as átonas finais de "only" e "watery". Aliás, "watery" está entre vírgulas, o que visualmente destaca a palavra, levando-nos a pausar antes e depois de lê-la, fazendo dela uma unidade rítmica. Chama a atenção porque até então nenhuma outra palavra fora pontuada deste modo ou recebera esta espécie de ênfase. E é algo que vai se repetir na terceira parte do poema.

$\mathrm{Na}$ terceira ária, as linhas são mais longas, as palavras se espalham, diversos versos começam apenas bem adiante na linha, conduzindo nosso olhar. Em termos métricos, é irregular. Há versos sem métrica alguma, mas há outros em que predomina este ou aquele pé. Esta irregularidade é um dos indicadores do "modo de significar" do poema: o poeta se detém em um ritmo por certo tempo, depois se solta, passando a um movimento mais livre, depois retoma outro pé métrico, e assim por diante. Cria assim um movimento, uma dinâmica de idas e vindas entre momentos de ritmos mais marcados e momentos mais "frouxos", que traduz, em termos rítmicos, certo acaso e imprevisibilidade da linguagem. De todo modo, nesta terceira parte, a coesão é dada pela sonoridade, especialmente nos três últimos versos, nos quais quase todas as palavras ecoam outras por meio de aliterações e assonâncias.

"Oh to be an angel', devaneia o poeta, embora logo pontue a não existência dos anjos, com o parênteses: "(if there were any!"). Mas o devaneio persiste, e a graça destes versos está no modo casual como é narrada a "subida" ao céu. O anjo de O'Hara parece querer apenas descansar um pouco de uma festa para depois retomá-la, sem maiores preocupações com a eternidade. De fato, "Oh to be an angel' é composto por pés trocaicos, um pé comum em versos infantis da língua inglesa. É como se o poeta reforçasse certo caráter lúdico de seu devaneio. Em relação às quebras de linha - ao contrário de outros poemas/momentos, em que estas podem criar estranhamentos -, nos versos iniciais desta terceira ária elas provocam uma aceleração da leitura, como se O’Hara encenasse a velocidade com que o anjo sobe e desce do céu. No segundo verso, há uma predominância de pés jâmbicos, que, por sua vez, também "facilitam" a leitura (como dissemos anteriormente, o jâmbico é o pé mais "natural” em inglês), e a rima incompleta entre "around" e "down" reforça a ligação entre o segundo e o terceiro verso. E "come down", no terceiro verso, mimetiza, na linha que cai e se desloca, a descida do anjo.

Na segunda "estrofe" dessa ária, o primeiro verso é composto completamente por pés datílicos, criando assim ainda outra dinâmica rítmica. No segundo verso, destaca-se a poluição sonora, caracterizada pela cacofônica aliteração entre "glaringly" e "ugly", com a ocorrência de três encontros consonantais /gl/. Em 
seguida, esta cacofonia é descrita pelos três verbos que descrevem sons. E, neste segundo verso, encontramos também três péons primos, os quais, aqui, como na segunda "ária", aparecem em momentos de "negatividade" (lá em cima, a falta de caráter do passarinho; aqui, caracterizando a poluição sonora).

A terceira e última estrofe traz uma espécie de redenção, um certo descanso dos olhos cansados, da malícia do passarinho, dos barulhos incômodos, do constante movimento. $\mathrm{O}$ anjo, invisível e silencioso, está suspenso entre as árvores, o azul do céu e a escuridão, e ouve o mínimo som imaginável: o som do ar. No primeiro verso, temos aliterações em /b/, /p/ e / t/ em quase todas as palavras, como se fossem breves estalos ao longo da linha. No final do verso, "invisible" aparece de modo semelhante a "watery" na "ária" anterior: entre vírgulas, a palavra única exige pausa, fica como que suspensa, reforçando assim o sentido de invisibilidade. No segundo verso, há três aliterações em /d/ - "iridescent", darkness", "beyond" - e duas com a sibilante /s/, que surgem ainda no verso seguinte, em "silent" e em "listening". Aliás, "silent", assim como "invisible", também consiste de uma única palavra entre vírgulas (embora a vírgula que preceda esta palavra esteja na linha anterior), enfatizando o silêncio. No terceiro verso, O'Hara usa novamente o "falling rhythm" do péon primo - "listening to" - e a simetria com a aparição anterior do péon chama a atenção porque o pé também é construído por um verbo no gerúndio ("clattering"). Além disso, ao colocar "listening to" no final do verso, estrutura que sintaticamente pede uma continuação, que antecipa algo, O’Hara parece chamar a atenção para o próprio ato de ouvir. O derradeiro verso é predominantemente jâmbico, com apenas uma pequena falha no segundo " air". E a justaposição de acentos parece desacelerar ainda mais um verso já bastante lerdo pelas pausas naturais depois dos dois primeiros airs. Mas o mais marcante aqui são as três repetições de "air", que fazem o poema ficar, literalmente, cheio de ar. Além disso, esse verso parece enfatizar as vogais de uma forma que contrasta com as constantes aliterações dos versos anteriores.

Quanto à tradução, ela é rítmica e sonoramente mais inconstante do que o original. Neste, na primeira "ária”, encontramos basicamente três tipos de pés, que coincidem com mudanças na esfera semântica. Na tradução, também predominam três ritmos diferentes, mas eles são menos constantes: pés anapésticos nas primeiras três linhas, pés péons quartos nos dois versos seguintes e pés anfíbracos no penúltimo verso. Mas, em termos de ecos sonoros produzidos por aliterações e assonâncias, na tradução existem em bem menor quantidade. Há a rima toante entre "gato", "balançado" e "rabo"; há também um certo domínio do som /ã/ em "tantas", em "elefante" e em "balançado"; e, na linha quatro, a aliteração em 
"b” ("balançado", "rabo”). Na tradução, o penúltimo verso é o único mais regular, composto por três pés anfíbracos. Com "batem e se esbarram" traduzimos proximamente o que ocorre em "banging about", reproduzindo o mesmo número de sílabas por verso e a aliteração em /b/. Por ser mais regular, este verso contrasta com os versos anteriores, criando uma nova dinâmica rítmica. No verso final, perdemos tanto os pés jâmbicos como a assonância, tão marcante, de "my tired red eyes". Mas ao menos a repetição do som /U/ em "dentro", "olhos" e "cansados" dá uma espécie de coesão interna ao verso.

$\mathrm{Na}$ segunda ária, para recriar certo tom moralizante de fábula infantil, usamos "cantarola" e "um canto de coragem". Além disso, no primeiro verso, ocorre uma dupla ocorrência da célula “/ - - - / -", que aparece ainda uma outra vez alguns versos adiante, o que de algum modo contribui para certa regularidade rítmica. A tradução de "alas!" é delicada; por ora, ficamos com "oh! céus!". Na sequência, enquanto no original há a repetição de células métricas entre "mischievously-hideousness", na tradução conseguimos apenas uma rima com o par "travessura-feiura". No verso final, fizemos uma assonância entre "álamos" e "aguados", compensando um pouco a perda das aliterações em /f/ alguns versos acima.

$\mathrm{Na}$ terceira ária, nas três primeiras linhas, foram mantidas as quebras de linha e o tom casual com que o poeta narra a subida do anjo ao céu, mas perdemos a rima entre "around-down". Na segunda estrofe, a marcante aliteração em "glaringly ugly" foi apenas parcialmente reproduzida com "fulgurantemente feio", mas ao menos algo de sua "deselegância" foi preservada. Nesta mesma estrofe, reproduzimos as rimas ocasionadas pela terminação verbal, como no original, com "estalando", "estourando" e "arfando". Neste trecho, mais do que traduzir fielmente o significado de cada um destes verbos no original, privilegiamos a sensação mais geral de barulhos incômodos. $\mathrm{Na}$ terceira estrofe, felizmente, conseguimos preservar boa parte da marcante sonoridade do original. Na primeira linha, temos aliterações em /t/ e /d/ e assonância em /a/. Na segunda linha, aliterações em /d/. No penúltimo verso, "ouvindo ao", em final de linha, parece conseguir um efeito parecido ao de "listening to", criando uma espécie de atenção ao próprio ato de ouvir, além de costurar sonoramente o verso com as três assonâncias em /o/. Em termos rítmicos, no último verso, não foi mantido o pé jâmbico, mas ao menos reproduzimos as pausas naturais depois dos dois primeiros "ares". E conseguimos criar um verso em português que, como o inglês, parece repleto de "ar", tanto na repetição vocabular como embutido na palavra "tornar". Estas repetições, mais as repetições da vogal /o/, dão a este verso uma qualidade sonora semelhante ao original, que contrasta com as aliterações dos versos anteriores. Esperamos, 
assim, ter recriado em português certo "volume", certo "ar", que se faz sentir nos derradeiros versos do poema de O'Hara.

\section{Referências}

ABRAMS, M. H., et al. "Poetic forms and literary terminology". In: The Norton anthology of English Literature. Vol. 2, 3 ed. Nova York: Norton, 1974.

ASHBERY, John. Introduction. In: The collected poems of Frank O'Hara. Edited by Donald Allen. Berkeley, Los Angeles, London: University of California Press, 1995.

BRITTO, Paulo Henriques. A tradução literária. Rio de Janeiro: Civilização Brasileira, 2012. . "Para uma avaliação mais objetiva das traduções de poesia". In: As margens da tradução. Org. Gustavo Bernardo Krause. Rio de Janeiro, FAPERJ/Caetés/UERJ, 2002, pp. 54-67. MONTGOMERY, Will. “In fatal winds': Frank O'Hara and Morton Feldman”. In: Frank O'Hara Now - new essays on the New York poet. Liverpool: Liverpool University Press, 2010, pp. 195-201.

O'HARA, Frank. The collected poems of Frank O'Hara. Edited by Donald Allen. Introduction by John Ashbery. Berkeley, Los Angeles, London: University of California Press, 1995.

"Interview with Edward Lucie-Smith". In: Standing still and walking in New York. Edited by Donald Allen. Bolinas, California: Grey Fox Press, 1975.

PERLOFF, Marjorie. Frank O'Hara: poet among painters (with a new introduction). Chicago and London: The University of Chicago Press, 1998. 